\title{
Introduction: A primer on information and influence in animal communication
}

\author{
ULRICH E. STEGMANN
}

What is surprising is that, despite this intensive study, the whole subject [of animal communication] is extremely confused, largely because of the definitions of the various terms that have been used. While this was already true when the first edition of this book was written, the confusions have now reached monumental proportions, with leading theorists even disagreeing as to what should properly be called 'a signal' or 'communication'.

Marian Dawkins (1995, p. 72)

[T] here is widespread and often unrecognized confusion about the kinds of signal that exist, the mechanism responsible for their evolution, and the terms to be used to describe them ... So it may be that a disagreement about terminology in a particular case is not about theories, or the words used to describe them, but about what the world is like.

John Maynard Smith and David Harper (2003, p. 2)

\section{Introduction}

A midsummer evening in a temperate forest: male fireflies emit pulses of light from specialised organs as they fly about in search of females. Females respond by emitting their own light pulses, which prompt males to approach them. A dialogue of light pulses ensues until the males have located the females (Lewis \& Cratsley, 2008). Mate recognition in fireflies illustrates some basic features of animal communication: a sender sends a physical signal, which is perceived by a receiver who responds to it. In fireflies the initial sender is the male, whose signal is the light pulse, and the receiver is the responding female. ${ }^{1}$

\footnotetext{
1 The roles of sender and receiver reverse when the female emits her own light pulse. Animal Communication Theory: Information and Influence, ed. Ulrich Stegmann. Published by Cambridge University Press. C Cambridge University Press 2013.
} 
Signals are physical events, behaviours or structures to which receivers respond. Yet they are more than that, according to the standard view in ethology (e.g. Hauser, 1996; Bradbury \& Vehrencamp, 2011a). As the colloquial meaning of 'signal' suggests, animal signals are events that convey information to receivers, where information is the content of a signal, or what the signal is about. For instance, the light pulses of fireflies reveal information about location, motivational state and species identity; the light pulses of a male convey, "Here I am in time and space, a sexually mature male of species X that is ready to mate. Over.” (Lloyd, 1966, p. 69).

However, such explicit specifications of information contents are rare (e.g. Owren \& Rendall, 1997), not least because identifying specific contents is difficult (Cheney \& Seyfarth, 1990; Hauser, 1996). Normally contents are circumscribed in vaguer terms, such as 'information about food', or they are invoked indirectly by classifying signals as, for instance, predator or alarm calls. Yet the underlying assumption is always that signals carry information in the sense of having some more or less specific content. Unsurprisingly then, information has found its way into formal definitions of signals and communication: communication is often defined as the process of conveying information from senders to receivers by means of signals, and signals as the behaviours or structures that senders evolved in order to convey information (Table 1).

Table 1 Examples of informational and non-informational definitions of animal signals and communication. Note that both Wilson (1975) and Maynard Smith and Harper (2003) excluded information only for the purposes of defining signals and communication; they did not reject the idea that both phenomena involve information.

\begin{tabular}{|c|c|c|}
\hline & Informational & Non-informational \\
\hline Signal & $\begin{array}{l}\text { “[Signals are] behavioral, } \\
\text { physiological, or morphological } \\
\text { characteristics fashioned or } \\
\text { maintained by natural selection } \\
\text { because they convey information } \\
\text { to other organisms.” (Otte, 1974, } \\
\text { p. } 385)\end{array}$ & $\begin{array}{l}\text { “We define a 'signal' as any act or } \\
\text { structure that alters the behaviour } \\
\text { of other organisms, which evolved } \\
\text { because of that effect, and which is } \\
\text { effective because the receiver's } \\
\text { response has also evolved.” } \\
\text { (Maynard Smith \& Harper, 2003, } \\
\text { p. 3) }\end{array}$ \\
\hline Communication & $\begin{array}{l}\text { "I consider communication to be any } \\
\text { sharing of information between } \\
\text { entities - in social communication, } \\
\text { between individual animals." } \\
\text { (Smith, 1997, p. 11) }\end{array}$ & $\begin{array}{l}\text { "Biological communication is the } \\
\text { action on the part of one organism } \\
\text { (or cell) that alters the probability } \\
\text { pattern of behavior in another } \\
\text { organism (or cell) in a fashion } \\
\text { adaptive to either one or both the } \\
\text { participants." (Wilson, } 1975, \text { p. 176) }\end{array}$ \\
\hline
\end{tabular}


Tail-flag cycles $\mathrm{min}^{-1}$

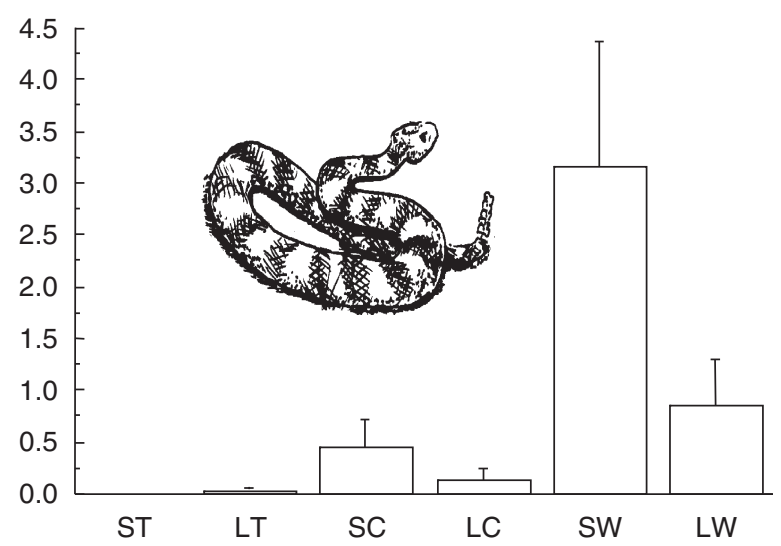

Figure 1 Mean rate (+SE) of tail flagging by squirrels during the first 2 minutes following playback of soft and loud tones (ST and LT, respectively) and of rattling sounds of small (S) and large (L) as well as cold (C) and warm (W) rattlesnakes. Squirrels flagged their tails significantly more in response to rattles than to tones, and more to rattles from warm snakes than to rattles from cold snakes. Warm snakes produce rattles that are both louder and have a higher click rate than those produced by cold snakes, which are less dangerous to squirrels. Graph reproduced with permission from Swaisgood et al. (1999); rattlesnake reproduced with permission from Richard Coss.

As structures that evolved to convey information, signals are typically contrasted with cues, which are behaviours or structures that convey information without having evolved for this purpose (e.g. Otte, 1974; McGregor, 1993; Hasson, 1994; but see Hauser, 1996). Rattling by rattlesnakes has probably evolved to ward off predators by conveying the information that the snake is venomous, i.e. rattling is a signal. But rattling can be a cue as well (Swaisgood, Rowe \& Owings, 1999). The click rate and dominant frequency of the rattling sound of Pacific rattlesnakes correlate with a snake's body temperature and size, respectively (Rowe \& Owings, 1990). California ground squirrels use these sound properties to adjust their degree of vigilance. Squirrels become more vigilant in response to rattling sounds from warmer snakes (Figure 1; Swaisgood et al., 1999), which are more agile and therefore more dangerous. For the squirrels, click rate and dominant frequency thus carry information about snake temperature and size, and they are cues because they did not evolve in order to convey such information.

Although information is a central and entrenched concept in animal communication studies, it seems possible to describe communication without it. The first paragraph of this introduction sketched firefly communication simply 
in terms of what some individuals do (emitting a light pulse) and how others respond (emitting another light pulse/approaching). We can even define signals and communication without appeal to information (Table 1). Why then introduce apparently intangible postulates such as content, message, meaning or information? Why not do without them? Doing away with information concepts, minimising their role or supplementing them with concepts like manipulation is what some ethologists advocate (Dawkins \& Krebs, 1978; Johnstone, 1997; Owren \& Rendall, 1997; Owings \& Morton, 1998; Rendall, Owren \& Ryan, 2009; Carazo \& Font, 2010). Questions about the legitimacy of information will be addressed later in this chapter. The following section focuses on the concept of information itself.

\section{Information}

\section{Colloquial information}

Signals are taken to convey information in the sense that they are about something, or have content (e.g. Halliday, 1983; Dawkins, 1995). But what does it mean to say that signals have content? This question is rarely addressed explicitly. Yet judging by how terms such as 'information' are employed in practice, it appears that much work in animal communication is based on three distinct but closely related answers (I will refer to these as 'content 1' etc. later in this introduction).

\section{Predictions and knowledge}

Many authors use 'information' interchangeably with what receivers come to know (e.g. Krebs \& Dawkins, 1984; Seyfarth \& Cheney, 2003; Bradbury \& Vehrencamp, 2011a), what they infer (e.g. Krebs \& Dawkins, 1984; Slocombe \& Zuberbühler, 2005) or what they predict when perceiving a signal (e.g. Smith, 1997; Seyfarth et al., 2010). In other words, a signal's information content is often equated with what receivers predict, infer or learn from it. And this practice suggests a first answer to what having content consists in: signals have content (or, equivalently, carry information) when they enable receivers to predict something from their occurrence.

Predicting is frequently understood in a qualitative sense (e.g. Krebs \& Dawkins, 1984; Smith, 1986; Seyfarth et al., 2010). There is, however, a quantitative framework for modelling predictions: statistical decision theory (Bradbury \& Vehrencamp, 2011a; see also Ch. 3). The basic idea in applying statistical decision theory is that animals constantly face decisions about how to act and that they use information (knowledge) to choose among alternative courses of action. Animals come equipped with some degree of background knowledge about the probability 
of certain events, which derives from earlier experiences and/or from heritable biases due to past selection. In order to achieve optimal decisions, animals continually update their prior information by attending to appropriate current events.

Consider contests among red deer stags over access to females. Frequent components of stag contests are roaring matches, which are usually won by the more frequently roaring male (Clutton-Brock \& Albon, 1979). Faced with a roaring harem-holder, a challenger must decide whether to retreat or keep roaring. Stags base their decisions on an estimate of their opponent's fighting ability. Fighting ability comes in degrees, but let us assume for illustrative purposes that rivals categorise one another as being either weak $(W)$ or strong (S). If prior knowledge suggests to a male that its rival is as likely to be weak as he is strong $[P(W)=P(S)=0.5]$, then such knowledge is of little help in deciding whether or not to retreat. However, fighting ability correlates with roaring: weak males roar less frequently than strong males (Clutton-Brock \& Albon, 1979; Reby et al., 2005). Males can use knowledge of this correlation to predict the fighting ability of opponents (Box 1).

\section{Box 1 A simple application of statistical decision theory}

According to statistical decision theory, predicting or inferring something from the occurrence of a signal amounts to calculating a conditional probability. A conditional probability is the probability of an event or state on the condition that some other event or state has occurred. Inferring something from a signal involves calculating the conditional probability of an event on the condition that the animal has observed that the signal has occurred. So, when a stag infers the fighting ability of a rival (the state) from his roar (the signal), he effectively 'calculates' the conditional probability that his rival has a certain fighting ability on the condition that he roars with a certain frequency.

Suppose that stags are either weak $(W)$ or strong $(S)$ and they either roar frequently $(F)$ or infrequently $(I)$. If a stag perceives his rival roar frequently, then the stag calculates two conditional probabilities: the probability that (1) the rival is weak on the condition that he roars frequently and the probability that (2) the rival is strong on the condition that (again) he roars frequently. To simplify matters, we will only consider how the stag calculates probability (1), which is written $P(W \mid F)$, where 'l' means 'given' (not to be confused with '/, the symbol for division). One way to calculate $\mathrm{P}(\mathrm{W} \mid \mathrm{F})$ is to use Bayes' theorem: 


$$
P(W \mid F)=\frac{P(W) \times P(F \mid W)}{P(W) \times P(F \mid W)+P(S) \times P(F \mid S)}
$$

In order to calculate $P(W \mid F)$, the stag needs some background knowledge. First, he needs to know how probable it is to encounter rivals that are weak and rivals that are strong. These are the 'prior probabilities', $P(W)$ and $P(S)$. They are independent of having heard a rival's roar.

Second, the stag needs to know how strongly roaring correlates with fighting ability. Such correlations are estimated as the conditional probabilities that a certain type of signal will be produced by the sender (or perceived by the receiver) given a certain state of the world. With two types of signal and two states there are four conditional probabilities:

\begin{tabular}{lll}
\hline \hline & \multicolumn{2}{c}{ State or event in the world } \\
\cline { 2 - 3 } Signal & Strong male $(S)$ & Weak male $(W)$ \\
\hline Frequent roaring $(F)$ & $P(F \mid S)$ & $P(F \mid W)$ \\
Infrequent roaring $(I)$ & $P(I \mid S)$ & $P(I \mid W)$ \\
\hline \hline
\end{tabular}

This table is a coding matrix. It specifies the degree to which a state or event in the world affects the probability that a signal will be produced (or perceived). For instance, it specifies how the fact that a male is weak affects the probability that he roars frequently, $P(F \mid W)$ (this is the converse of the probability the stag needs to calculate, $P(W \mid F))$.

The stag can now 'update' his prior probability that the rival is weak. This process can be modelled with Bayes' theorem. Suppose the stag's prior probability that the rival is weak is $P(W)=0.5$. So, without having heard the rival's roar, the rival is equally likely to be weak or strong $[P(S)=0.5]$.

Suppose also that the stag knows about the following correlations between roaring and fighting ability: strong males roar frequently $80 \%$ of the time and infrequently $20 \%$ of the time $[P(F \mid S)=0.8, P(I \mid S)=0.2]$, whereas weak males roar infrequently $95 \%$ of the time and frequently $5 \%$ of the time $[P(I \mid W)=0.95, P(F \mid W)=0.05]$. Inserting these values into Bayes' theorem yields:

$$
P(W \mid F)=\frac{0.5 \times 0.05}{0.5 \times 0.05+0.5 \times 0.8}=0.06
$$

The result shows that the stag has learned something from the rival's frequent roaring. Hearing the rival roar frequently reduces the stag's estimate of the probability that his rival is weak from an initial $50 \%$ to a mere $6 \%$. In other words, the stag can now be 
fairly confident that the rival is not weak. He can adjust his behaviour accordingly.

Two points are worth emphasising. First, when a receiver has used a signal to update its estimate of the probability of certain events, it has just made the first step. In order to use what it has learned to guide its behavioural response, the receiver also needs to take into account the fitness costs of making correct as opposed to incorrect choices of action (Bradbury \& Vehrencamp, 2011b). Second, updating critically depends on what the receiver knows about the correlations between signals and world states (the coding). From the point of view of statistical decision theory, the signal by itself, without the coding, carries no information (J. Bradbury, personal communication). As mentioned in the main text, a signal's carrying information can be understood as enabling receivers to infer something from it. Since without coding receivers cannot infer anything from a signal, the signal itself carries no information.

Statistical decision theory is not only a quantitative tool for modelling how and what receivers predict from signals. Ecologists studying foraging behaviour, too, understand the idea that cues carry information/content as a matter of allowing predictions, and they employ statistical decision theory to model this process (e.g. Valone, 1989; Giraldeau, 1997; Danchin et al., 2004; Stephens, 2007; Wagner \& Danchin, 2010). Indeed, a rich and partly controversial taxonomy of types of information has been developed along these lines (e.g. Danchin et al., 2004; Wagner \& Danchin, 2010). One of the proposals is to distinguish between private and public information. European starlings probe the ground for insects and so acquire knowledge about patch quality, which is then used in foraging decisions, for instance when to leave the current patch for another (private information: knowledge of $x$ gathered from direct contact with $x$ ). Instead of probing for insects themselves, individuals may also gain this information by observing their flockmates' probing success (Templeton \& Giraldeau, 1996). The latter is public information: knowledge of $x$ gathered from a cue of $x$.

It is tempting to believe that predictions, inferences and knowledge imply cognitive or psychological processing on the receiver's part, perhaps even conscious awareness. Indeed, key steps of decision-making have neural correlates (reviewed in Lee, 2010, and Bradbury \& Vehrencamp, 2011c). But cognitive capabilities are implied in neither foraging ecology nor animal communication. Quantitative and informal work in these areas remains explicitly neutral on 
the mechanistic aspects of deriving predictions (Danchin et al., 2004; Stephens, 2007; McNamara \& Dall, 2010; Bradbury \& Vehrencamp, 2011a). In some species, inferences from signals may just consist in simple learned associations or evolved dispositions (Krebs \& Dawkins, 1984; Smith, 1997). Likewise, predictions from cues may consist in non-cognitive processes (Danchin et al., 2004; McNamara \& Dall, 2010).

\section{Mental representations}

A more demanding view about the nature of signal content emerged in work on 'referential' signals. Referential signals allow receivers to infer features of the external environment instead of, or in addition to, features of the sender (variously labelled "semantic", "referential”, "symbolic"; reviewed in Hauser, 1996). The alarm calls of vervet monkeys are a well-known example (Seyfarth, Cheney \& Marler, 1980). Vervets emit three acoustically different types of calls in response to three different types of predators: leopards, eagles and snakes (Figure 2). Listeners respond to the calls in a way appropriate for the type of predator. For example, calls emitted in response to approaching eagles prompt vervets to seek cover in bushes, whereas calls emitted in response to snakes elicit upright posture and scanning of the ground. These calls appear to function like labels for things in the world, in this case types of predators, much like some words in human languages (Hauser, 1996; Cheney \& Seyfarth, 2007).

Animal signals are called "functionally referential" when they function like labels (e.g. Marler, Evans \& Hauser, 1992; Macedonia \& Evans, 1993; Fischer et al., 1995; Evans \& Evans, 1999; Manser, Bell \& Fletcher, 2001). This leaves open whether the signals are like words in the additional sense of eliciting mental representations of the referent in the minds of receivers, i.e. internal representations which mediate receiver responses. Such "representational" (Hauser, 1996; Evans \& Evans, 2007) or “conceptual” signals (Zuberbühler et al., 1999) are taken to be close to human words on the basis of assuming that human words refer to things indirectly, via something in the mind of receivers, an abstraction or concept (e.g. Cheney \& Seyfarth, 1990; Hauser, 1998) or a mental representation (Evans, 1997; see also Box 2). According to the most demanding view of informational communication, referential signals have content only in the case that receivers infer or predict something from it by means of internal representations, or even mental "images" (Maynard Smith \& Harper, 2003; Seyfarth \& Cheney, 2003; cf. Fedurek \& Slocombe, 2011; Wheeler et al., 2011). Accordingly, the term 'information' is sometimes used to denote whatever a receiver's mental representations encode (Maynard Smith \& Harper, 2003; Seyfarth \& Cheney, 2003). 
A

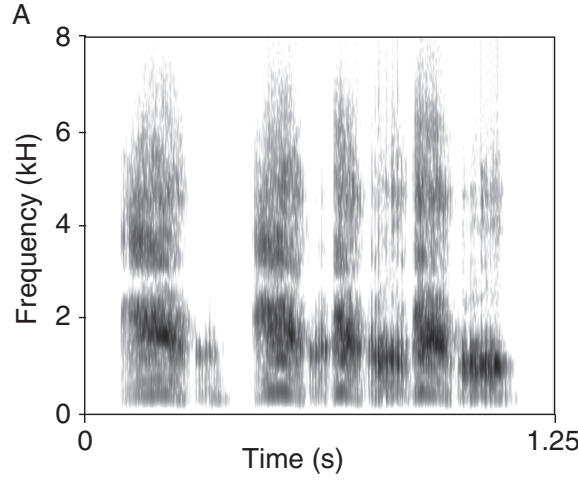

C

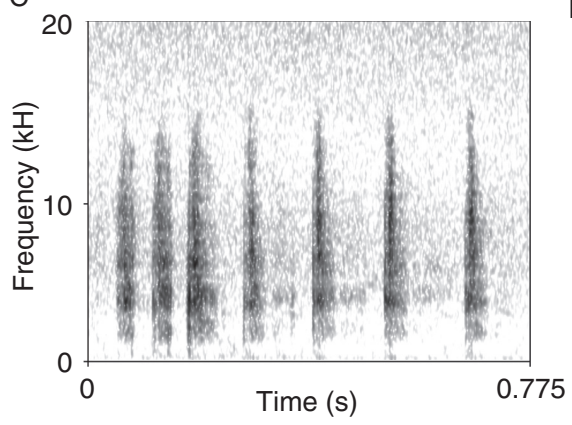

B
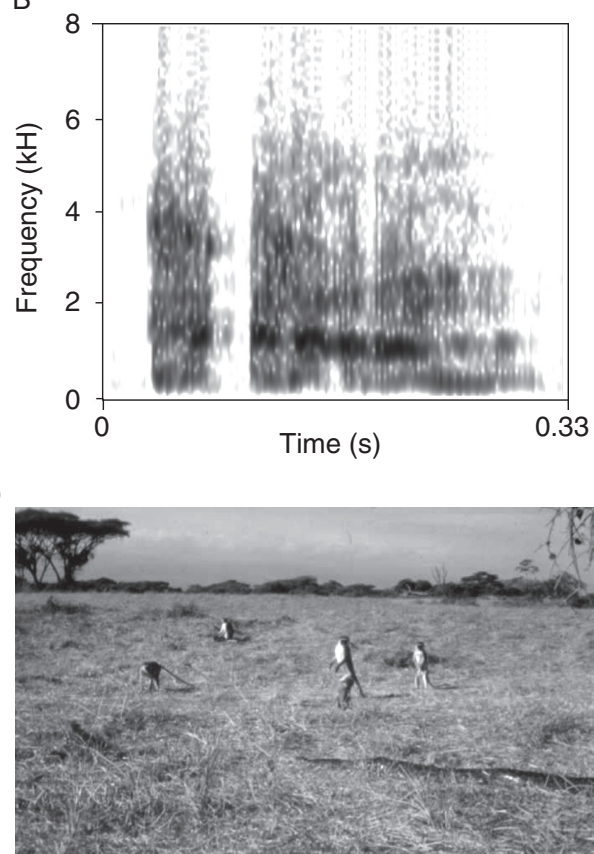

Figure 2 Vervet monkeys (Chlorocebus aethiops) give acoustically distinct alarm calls in response to leopards (A), eagles (B) and snakes (C). The acoustic features of alarm calls also differ from the predators' own vocalisations (e.g. vervet eagle alarm calls do not sound like eagle shrieks). When encountering one of these predators directly, vervets react in a manner specific and adaptive to the kind of predator involved, e.g. standing upright and scanning the ground when perceiving a python (D: python approaching from the lower right-hand side of the photo). Playback experiments in the wild showed that simply hearing an alarm call given in response to one type of predator, without perceiving the predator itself, triggers the appropriate behavioural response. Variations in acoustic features that may be associated with a sender's fear (e.g. call amplitude, or loudness) have no significant effect on the type of response. For these reasons, vervet alarm calls are considered to be "referential" or "semantic", i.e. "signs [that] refer to objects in the external world" (Seyfarth et al., 1980, p. 1070). The study by Seyfarth et al. (1980) generated much interest in the presence of referential signalling in other species (reviewed in Seyfarth et al., 2010; Fedurek \& Slocombe, 2011; see Radick, 2007 for a history of playback experiments). A-C: Sonograms provided by Robert Seyfarth. D: Photo by Richard Wrangham.

Correlation

What enable animals to make predictions from signals are correlations between signals and other states or events. In some contexts, correlations are deemed sufficient for signals to have content. The state or event with which the 


\section{Box 2 Learning theory}

Animals that repeatedly experience associations between two events can change their capacity for certain behaviours ("associative learning"; see Shettleworth, 2001, for terminological ambiguities). One of the best-known forms of associative learning is classical conditioning, which involves unconditioned reflexes. An unconditioned reflex is a behavioural response that is always triggered by a certain type of stimulus (such as salivation triggered by food). In classical conditioning experiments, animals are repeatedly exposed to pairings of the original (unconditioned) stimulus with a second type of event that does not normally trigger the reflexive response. After a while, animals perform the behaviour simply after perceiving the new event on its own. Pavlov famously exposed dogs to both food and a ringing bell, and the dogs eventually salivated in response to hearing the bell. What psychological and neural mechanisms are responsible for this change in the dogs' capacity to react?

According to associative theories of learning, training 'stamps in' the association between the new (conditioned) stimulus and the behavioural response. That is, animals acquire a rigid response to the conditioned stimulus by establishing an excitatory or inhibitory connection between them (S-R theories). Representational or cognitive theories of learning propose instead that training creates a connection between the conditioned stimulus and an 'expectation' of the unconditioned stimulus ( $\mathrm{S}-\mathrm{S}$ theories). The bell triggers a neural representation of food (or a representation of the relation between the two), and the animal reacts on the basis of this representation (reviewed in Lieberman, 2003; Shettleworth, 2010). The classic debate between associative and representational theories of learning is the background for the contrast some ethologists draw between rigid (or automatic) and representation-mediated responses (see 'Colloquial information').

Current research favours cognitive theories (Shettleworth, 2010). But it is acknowledged that there is evidence on both sides (Lieberman, 2003) and that the nature of the posited neural representations remains elusive (Gallistel, 2008). One of the strongest lines of evidence in favour of cognitive learning theories is thought to come from alarm calls in Diana monkeys (Shettleworth, 2001). Diana monkeys react in the same way to acoustically distinct vocalisations, e.g. to the shrieks of an eagle and to the eagle alarm calls of their conspecifics (see figure). This suggests that despite their differences, the two types of vocalisations evoke the same kind of mental 
A BASELINE

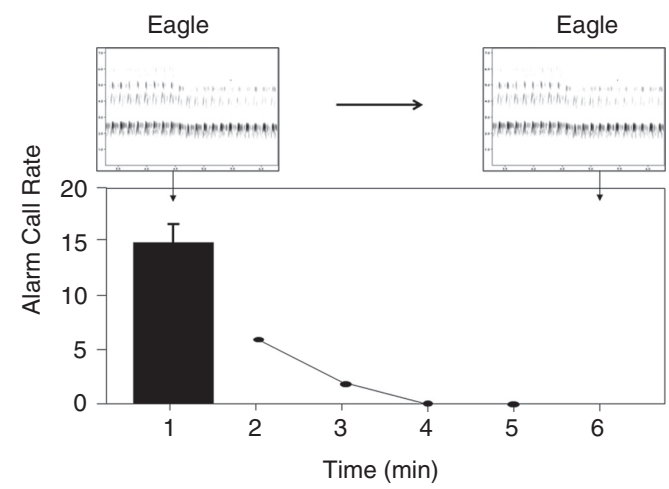

B

CONTROL

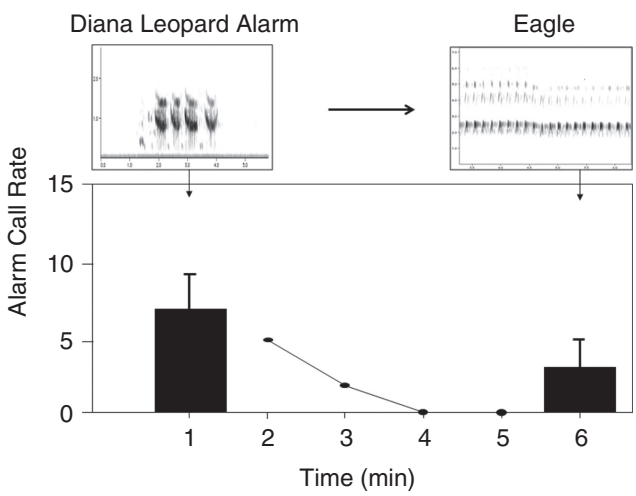

C

TEST

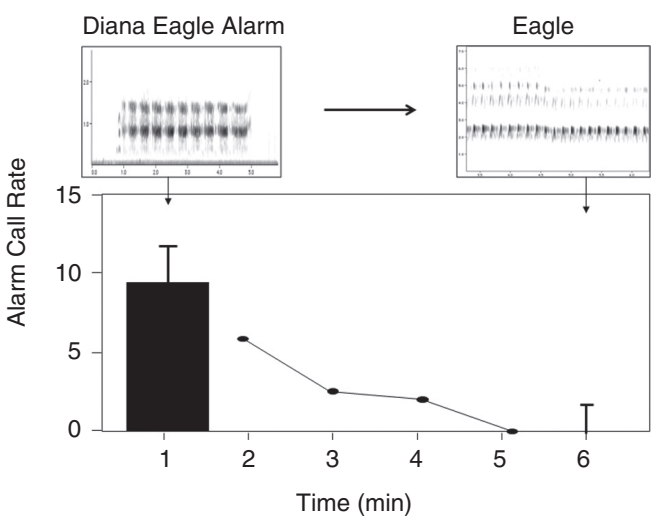

Figure Evidence for mental representations of signal referents by receivers (Zuberbühler et al., 1999). Diana monkeys produce different alarm calls in response to their predators (eagles and leopards). Females also call in response to the alarm calls of their male conspecifics. In this set of prime-probe experiments 


\section{Caption for Box 2 Figure (cont.)}

conducted in the wild, a group of females were played one type of vocalisation (prime) for 5 mins, followed by eagle shrieks (probe). After a strong initial response, females habituated within 5 mins to the prime. A, Baseline: primed with eagle shrieks, the females habituated after exposure to further eagle shrieks. B, Control: after habituating to the leopard alarm calls of males, females dishabituated in response to eagle shrieks. C, Test: after habituating to eagle alarm calls, females remained habituated to the acoustically distinct eagle shrieks. The experiment suggests that eagle alarm calls and the shrieks of an eagle carry the same information for females ('eagle approaching') whereas leopard alarm calls do not. More importantly, the experiment appears to reveal how females process the vocalisations: the fact that females treat acoustically distinct vocalisations as the same suggests that the female response is not simply triggered by the acoustic properties of vocalisations (otherwise the response should be different). Instead, the response is likely to be mediated by a "common associate, possibly a mental representation, of the predator category" (Zuberbühler et al., 1999, p. 41). The methodology of earlier work on vervet alarm calls did not allow this further conclusion. Modified with permission from Zuberbühler et al. (2009).

representation, which in turn mediates the same type of behavioural response (Zuberbühler, Cheney \& Seyfarth, 1999). In addition to these behavioural findings, there is also increasing neurophysiological evidence for mental representations in primate vocal communication: listening to calls activates the retrieval of associated visual representations (Gil-da-Costa et al., 2004), and the pre-frontal cortex has been implicated in the semantic processing of calls (reviewed in Romanski \& Ghazanfar, 2010; see also Ch. 14).

signal correlates, or to which it bears a causal relation, is then seen as the signal's content. Consider the waggle dance of honeybees, which correlates with the distance and cardinal direction of valuable resources such as flower stands (e.g. von Frisch, 1967). In the 1970s an acrimonious debate arose over whether bee recruits actually use the dance to find the resources, as von Frisch had claimed, or whether they use the dancer's odours instead. Interestingly, all participants of the 'bee language controversy' agreed that the dance carries spatial information; the contentious issue was only whether the recruits use its information (Dyer, 2002; Munz, 2005). Correlations obtain even if they are not exploited by receivers. This suggests that all sides of the debate implicitly agreed that the dance carries spatial information simply in virtue of its correlations with certain external factors. 
Smith's (1965) distinction between the "message" and "meaning" of signals is relevant here. The distinction is influential but also fairly unclear and controversial (e.g. Philips \& Austad, 1996; Bradbury \& Vehrencamp, 2011b). Perhaps Smith's "message" is best understood as what signals correlate with (content 3), and "meaning" as what receivers infer from signals (content 1).

\section{Mathematical information}

As has often been noted, information is sometimes employed in a quantitative sense, in addition to its colloquial meaning (e.g. Marler, 1961; Smith, 1965; Krebs \& Dawkins, 1984; Markl, 1985). Quantitative information features in studies which apply Claude Shannon's (1948) mathematical theory of communication to animal signals. Such studies measure what we know today as the Shannon entrophy of a signal, as well as its conditional entropy and its transinformation - all quantities of the mathematical theory of communication. One of the earliest studies of this kind explored the visual displays of hermit crabs. Hermit crabs perform several kinds of displays when other crabs intrude into their personal space (Hazlett \& Bossert, 1965; Laidre, 2009). They may, for instance, raise their chelipeds up and outwards, or raise one of their walking legs, or perform some other type of display (Figure 3).

A

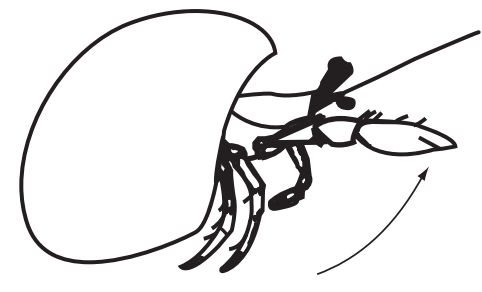

B

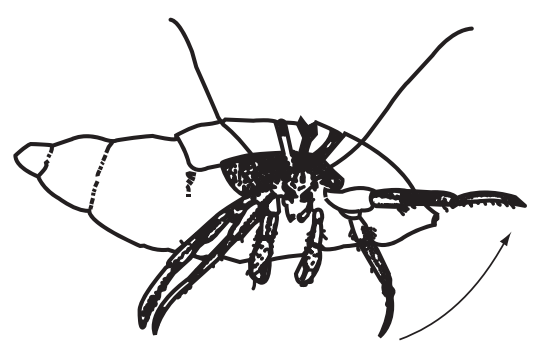

Figure 3 Hermit crabs can deter intruders by raising their limbs up and outwards. (A) Raising of the cheliped (clawbearing leg) in Anisopagurus pygmaeus. (B) Raising of a walking leg in Clibanarius cubensis. These visual displays were regarded as examples of threat signals, conveying the sender's intent for future agonistic opposition (e.g. Hazlett \& Bossert, 1965). The view that threat signals convey information about sender intentions was undermined subsequently by findings of poor correlations between signalling and future aggression, as well as theoretical analyses suggesting that signals of intent are particularly susceptible to invasion by cheaters. More recent studies, however, support the viability of intention signalling in hermit crabs. The lack of correlations is likely to have been due to ignoring confounding variables, especially receiver responses: when intruders retreat, senders do not back up their displays with attack (Laidre, 2009). Reprinted with permission from Hazlett and Bossert (1965). 
Hazlett and Bossert (1965) arranged encounters between pairs of crabs and counted how often crabs performed the various display types. They observed 6138 performances in total, of which 1121 were "major cheliped extensions". The cheliped rise therefore had a relative frequency of $1121 / 6138=0.18$. And since relative frequencies can serve as estimates of probabilities, the probability of a crab raising its cheliped was $P\left(d_{1}\right)=0.18$ (where $d_{1}$ stands for cheliped rise). The probabilities of the other displays (such as raising a walking leg) were calculated in the same way. Hazlett and Bossert (1965) then calculated the Shannon entropy of the entire signal repertoire by, first, multiplying the probability of a given display type with the logarithm of its probability, e.g. multiplying $P\left(d_{1}\right)$ by $\log _{2} P\left(d_{1}\right), P\left(d_{2}\right)$ by $\log _{2} P\left(d_{2}\right)$, and so on for all display types. For each type they thus obtained a product. They then summed the products to yield the Shannon entropy,

$$
H=-\sum_{i} P\left(d_{i}\right) \times \log _{2} P\left(d_{i}\right)
$$

where $d_{\mathrm{i}}$ denotes a kind of display (taking the logarithm to the base of 2 ensures that the unit is a 'bit'). Another important quantity is transinformation, which measures statistical dependencies between two sets of events (e.g. signals and responses).

Shannon entropy is sometimes referred to as a "measure of information" (e.g. Shannon, 1948) or even as "information content" (e.g. Quastler, 1958; Dingle, 1969; Wilson, 1975). So it is tempting to think that Shannon entropy is, after all, equivalent to (or a measure of) information in the colloquial sense. But this is not the case, as Shannon (1948), Quastler (1958) and many ethologists have acknowledged (e.g. Marler, 1961; Smith, 1965; Markl, 1985). Here is a consideration that can help to explain why this is the case. Suppose the various display types of hermit crabs are about different things, so that their information (content) differs. Suppose further that we calculate the Shannon entropy $(H)$ for the crab's display repertoire. Since $H$ is an average, all display types belonging to that repertoire will then have the same value of $H$, irrespective of their content. In other words, any two display types with different information (content) will have the same information $(H)$. Since colloquial information and $H$ can become separated in this way, they cannot be identical.

In other respects, however, the relation between the colloquial and mathematical sense of information remains unclear. For example, "technical" or "Shannon" information is often described as a reduction in uncertainty (e.g. Halliday, 1983; Krebs \& Davies, 1993; Seyfarth et al., 2010), which is also how the acquisition of knowledge by receivers is described (content 1; e.g. Quastler, 
1958; Wiley, 1983; Seyfarth \& Cheney, 2003; Bergstrom \& Rosvall, 2011; Wheeler et al., 2011). These practices suggest that for many researchers there is still some continuity between quantitative and colloquial information. To complicate matters, work in statistical decision theory offers a different yet explicitly quantitative approach to understanding information. A key quantity in this context is the change in the probability of a predicted event upon perceiving a signal (for similar measures see McNamara \& Dall, 2010; Skyrms, 2010; Bradbury \& Vehrencamp, 2011b).

The next section looks at manipulation, persuasion and influence (see also Chapters $2,6-7,9-10,16,18$ ). These notions tend to be used synonymously and are often advanced as alternatives to information.

\section{Manipulation and influence}

Richard Dawkins and John Krebs (1978) were among the first to advocate an explicitly non-informational approach to animal communication. Signals, they argued, do not evolve to convey information, but rather to manipulate or persuade (Box 3). Manipulation does not imply (malevolent) intentions on the part of senders. It only implies that signals evolve in order to prompt receivers to behave in ways beneficial to the sender, even if the behavioural response comes at the receivers' expense. The latter part of this claim, i.e. that signalling may disadvantage receivers, continues to draw particular attention (and criticism; see 'Arguments concerning manipulation' below). Indeed, manipulation is often understood as an interaction whose key feature is the fitness cost to receivers (e.g. Smith, 1986; Searcy \& Nowicki, 2005; Seyfarth et al., 2010; Bradbury \& Vehrencamp, 2011b; Wheeler et al., 2011).

However, proponents of manipulation insist that receivers need not necessarily suffer fitness costs when being manipulated (Owren, Rendall \& Ryan, 2010). This point has been illustrated with the mating calls of Engystomops frogs (Rendall et al., 2009). Engystomops frogs are a closely related group of species in which the males emit species-specific calls ('whines') to court females. The males of some species have evolved the ability to (sometimes) add a distinct call component ('chucks') to their whines, which makes the resulting calls more attractive to females. Female preference for chucks is a sensory bias that predates the evolution of chucks (Figure 4). Females find them hard to avoid because they affect highly conserved neural features. The chucks therefore 'manipulate' females without females suffering fitness costs by responding more strongly to calls with chucks (reviewed in Ryan \& Rand, 2003; but see Bradbury \& Vehrencamp, 2011b; see also Ch. 9). 


\section{Box 3 Signal evolution}

Among the key tasks in understanding the evolution of animal signals is specifying the selection pressures that shape signal design. Several sources of selection pressures have been identified, chief among them the physical environment and the sensory and neural capacities of receivers. Signals are selected for properties that make them detectable by the intended receivers in a given environment (reviewed in Bradbury \& Vehrencamp, 2011a).

The way selection operates raises a fundamental puzzle for the view that signals evolve to convey information (cf. Markl, 1985). Many modelling studies have their origin in responses to this puzzle. If signals evolve in order to convey information, then senders should benefit from conveying information. But senders do not always benefit from revealing their intentions (Krebs \& Dawkins, 1984). In addition, an honest signalling system in which all convey true information about themselves can be invaded by "cheaters" (e.g. Maynard Smith, 1976). Cheaters are animals that signal the presence of features they do not possess, e.g. aggressive intentions. Since cheaters benefit from misguiding receivers, their genes spread. Receivers eventually evolve to ignore the 'deceiving' signals, and this creates pressure on senders to cease signalling. How then could signals ever evolve to convey information?

Dawkins and Krebs' (1978) conclusion was that they do not evolve to convey information in the first place; they evolve to manipulate receivers instead (a view itself criticised as being evolutionarily implausible; see main text). Other theorists responded to this puzzle by seeking to identify evolutionary mechanisms that would allow signals to function as information transmitters. One of the most influential suggestions was that the production of signals about the features of senders must be so costly as to be restricted to senders that actually possess the features ("handicap" signals, Zahavi, 1975). Zahavi's suggestion initially met with skepticism, but over time a consensus emerged that some forms of costs can lead to honest or reliable signals (reviewed in Searcy \& Nowicki, 2005). Since the 1970s, five additional mechanisms ensuring signal reliability have been identified (Searcy \& Nowicki, 2005). The present consensus is that most signals are reliable on average, and that they must be reliable in order to evolve (Searcy \& Nowicki, 2005; Seyfarth et al., 2010; but see Rendall et al., 2009). Evolutionary perspectives are further explored in Chapters 15 and 16. 


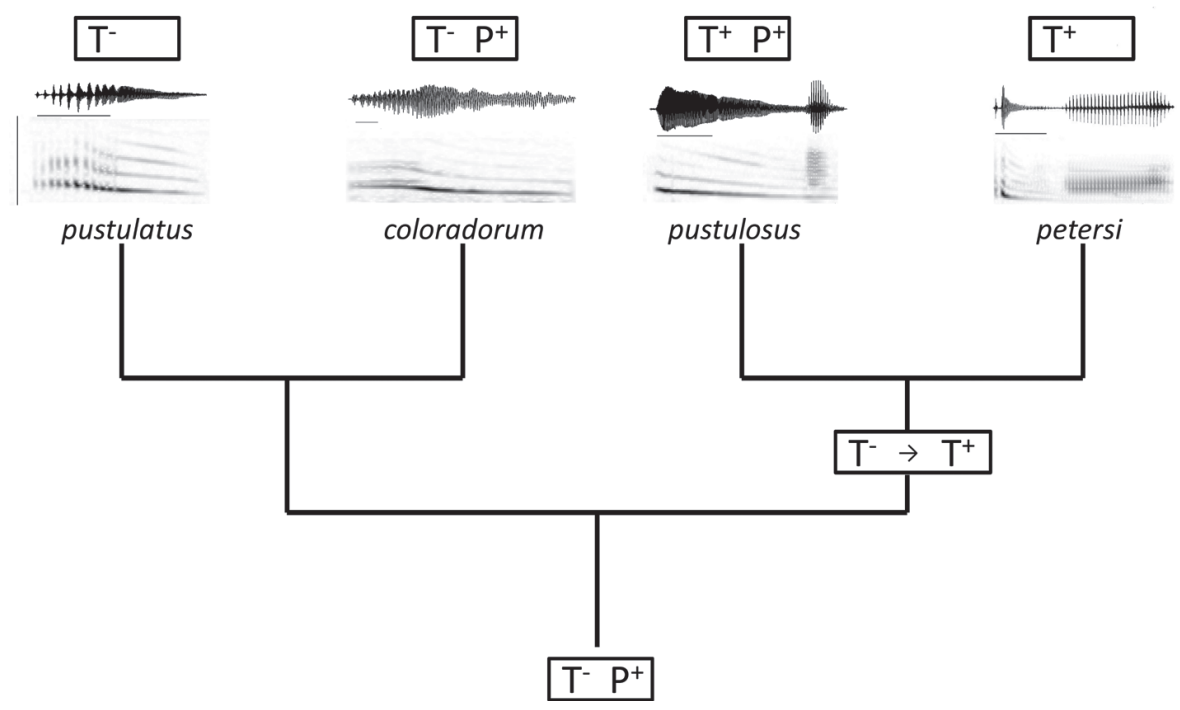

Figure 4 The evolution of male mating calls and female preferences of four species in the Engystomops (= Physalaemus) pustulosus species group. Each call is represented by a waveform (top) and a spectrogram (bottom; horizontal bar $=100 \mathrm{~ms}$, vertical bar $=0-5000 \mathrm{~Hz}$; all to the same vertical scale, but different horizontal scales). $\mathrm{T}^{-}$indicates the absence of the terminal chuck, in both $E$. pustulatus and E. coloradorum, while $\mathrm{T}^{+}$indicates the presence of the chuck in both $\mathrm{E}$. pustulosus and E. petersi. $\mathrm{P}^{+}$indicates that both E. coloradorum and E. pustulosus exhibit a preference for calls with chucks, despite the fact that the natural E. coloradorum call lacks a chuck; the preference was shown for an E. coloradorum call with E. pustulosus chucks appended to it. Analysis of the entire species group and several outgroup species (not shown) suggests that the ancestral condition of the species group is $\mathrm{T}^{-}$and $\mathrm{P}^{+}$(lower box) and that chucks evolved prior to the separation of E. pustulosus and E. petersi (box $\mathrm{T}^{-} \rightarrow \mathrm{T}^{+}$). The trait distributions on this cladogram therefore suggest that the evolution of chucks exploited a preexisting sensory bias in females (Kirkpatrick \& Ryan, 1991). Subsequent work has considerably added to this picture (e.g. Ryan \& Rand, 2003), but also challenged it (Ron, 2008). Redrawn by Michael Ryan from Kirkpatrick and Ryan (1991).

\section{Affect induction}

For contemporary proponents of the manipulation view, manipulation is primarily characterised in terms of the proximate mechanisms that elicit receiver responses. A prominent example is the "affect-conditioning model" of non-human primate vocalisations (Owren \& Rendall, 1997; later extended to other mammals in Owren \& Rendall, 2001). According to this model, primate vocalisations employ two basic mechanisms for influencing receiver behaviour, a direct and an indirect mechanism. 
The direct mechanism is the immediate impact of a call's acoustic properties on the receiver's sensory and nervous system. Primate squeaks, shrieks and screams, which include vervet monkey alarm calls, have abrupt-onset pulses with large frequency and amplitude fluctuations and are highly effective in evoking attention and arousal. The indirect mechanism relies on pairing vocalisations with emotion-inducing behaviours. For instance, dominant animals frequently antagonise subordinate group members with aggressive acts such as biting and chasing, which elicit arousal and affect in the subordinates and corresponding behavioural responses. Because the threat calls are produced in close temporal proximity to aggressive behaviours, receivers learn to associate threat calls with aggressive behaviour through classical conditioning. Eventually, threat calls become a conditioned stimulus: calls now suffice to elicit the motivational, emotional and behavioural responses that previously required aggressive behaviour (Owren \& Rendall, 2001).

Owren and Rendall (2001) argued that these two mechanisms underlie most primate vocalisations and concluded that "a great deal of primate vocal signalling may be quite unsophisticated, functioning merely to draw another individual's attention, change its arousal level, induce affect, or serendipitously pair the caller's voice with some positive or negative state in the listener" (p. 69). In other words, the reason that primate vocalisations are said to lack information is the unsophisticated nature of signal processing in receivers (not the fitness costs to receivers). Interestingly, this way of drawing the line between information and manipulation parallels the approach taken by some proponents of information, who regard informational communication as a matter of evoking mental representations in receivers and who contrast this kind of signal processing with automatic, reflexive reactions which they count as non-informational forms of interaction (see 'Colloquial information').

\section{Assessment/management}

Initially, Dawkins and Krebs (1978) portrayed communication as the process by which senders manipulate receivers. They later revised this view, conceding that information does play an important role in communication after all (Krebs \& Dawkins, 1984). They argued that receivers should evolve "mindreading" capabilities (not merely "sales-resistance", i.e. the ability to withstand sender manipulation). Mind-reading is the ability to use statistical regularities in order to "predict" an animal's future behaviour (an ability acquired through individual learning or evolution) or, as they saw it, the ability to gather information about senders. Mind-reading does not demand complex cognitive capacities, let alone the ability to attribute mental states to other animals (theory of mind). 
Krebs and Dawkins' (1984) view has found support (e.g. Johnstone, 1997; Carazo \& Font, 2010). Donald Owings and Eugene Morton (1998) further developed this view into the assessment/management approach, according to which animal communication is the interplay between management on the part of senders ("managers") and assessment on the part of receivers ("assessors"). Management consists in influencing the behaviour of assessors in ways that benefit the manager: "from the perspective of management, signals do not refer to anything; they are pragmatic acts emitted to produce an effect of variable specificity" (Owings \& Morton, 1997, p. 379). However, receivers are not merely passively used by managers. Assessors seek for cues that allow them to adjust their behaviour to prevailing circumstances. Assessment is the "active extraction of the cues needed for adaptive decision-making” (Owings \& Morton, 1998, p. 72). Importantly, since assessors learn something from attending to cues or signals, assessment is thought to yield information (see also Ch. 8).

While Owings and Morton endorse information as one aspect of communication, they emphasise that cognitive or "information-processing" mechanisms are only one of four types of mechanisms of assessment. The three others are motivational, perceptual and emotional mechanisms. One of Owings and Morton's (1997) examples for a motivational mechanism is the effect of songbird vocalisations on hormone levels. In simulated territorial intrusion (STI) experiments, a caged male (or artificial dupe) is placed into the established territory of another male together with a loudspeaker, which plays the song of a conspecific male. In some species, STI increases the blood levels of testosterone and luteinising hormone in the territory owner, in addition to causing aggressive behaviour (Figure 5; e.g. Wingfield \& Wada, 1989; McGlothlin et al., 2008; but see Apfelbeck \& Goymann, 2011). The call (signal) therefore influences the owner's neuroendocrine system (at least in conjunction with non-auditory cues, Wingfield \& Wada, 1989). Owings and Morton concluded that this is a communicative effect which can hardly be described as information transfer. Note that information is, again, tied to the proximate mechanisms by which signals have their effects on receivers.

\section{Evaluating informational and non-informational explanations of animal communication}

So far we have explored how the concepts of information and manipulation are understood and how they are employed in order to explain animal communication. Both informational and non-informational approaches have their proponents and critics. Doubts about the legitimacy of informational explanations have been raised repeatedly (e.g. Dawkins \& Krebs, 1978; 


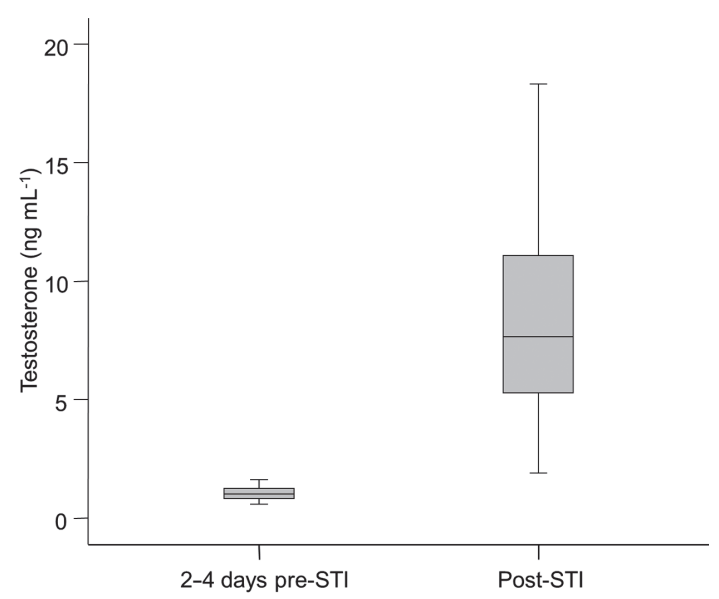

Figure 5 Testosterone levels in response to a simulated territorial intrusion in darkeyed juncos (Junco hyemalis). In a simulated territorial intrusion (STI), a caged male was placed inside the territory of another male and pre-recorded junco songs were played from a loudspeaker. After 10 minutes the territory owner was captured and a blood sample taken. Males presented with an STI displayed significantly elevated testosterone levels following the intrusion (horizontal line: median; shaded box: interquartile range; bars: range). Reproduced with permission from McGlothlin et al. (2008).

Owings \& Morton, 1997; Owren \& Rendall, 2001) and they have received a moderate degree of attention (e.g. Philips \& Austad, 1996; Seyfarth \& Cheney, 2003; Scott-Phillips, 2008; Carazo \& Font, 2010). An article by Rendall, Owren and Ryan (2009) brought these doubts to the forefront of ethological research, eliciting further responses (e.g. Font \& Carazo, 2010; Scarantino, 2010; Seyfarth et al., 2010; Bradbury \& Vehrencamp, 2011b; Ruxton \& Schaefer, 2011; Wheeler et al., 2011). The purpose of the following three sections is to introduce a few of the central arguments that have been proposed on either side. These sections are not intended to adjudicate or to provide a comprehensive survey.

Arguments in favour of information

Empirical support

The most straightforward argument for the appropriateness of information is empirical evidence (Seyfarth et al., 2010). Many studies now document structures or behaviours that (1) correlate with features of the sender or the environment and (2) elicit suitable responses in other animals (i.e. responses appropriate to the features with which the structures or behaviours correlate). One of the earliest studies to meet these criteria was Seyfarth, Cheney and Marler's (1980) seminal work on vervet monkeys described above. The three types of alarm calls are emitted specifically in response to three different types 
of predators (criterion 1). Furthermore, calls in the absence of non-acoustic cues are sufficient to prompt a behavioural response in receivers, and the response is appropriate for the type of predator that elicits a call (criterion 2). Alarm calls therefore enable vervets to 'predict' that a predator is approaching (at least if 'prediction' is understood in an undemanding sense; see 'Colloquial information'). And since signals are taken to carry information when they enable receivers to predict things from their occurrence, it follows that alarm calls carry information about specific types of predators.

Theoretical appeal

Another argument in support of the informational approach is its theoretical appeal (Seyfarth et al., 2010). The informational view is in line with cognitive approaches to learning theory, according to which learning is a matter of acquiring information, which in turn involves mental representations (Box 2). Furthermore, the approach has great explanatory scope. Explaining receiver behaviour in terms of information content abstracts away from the physical properties of signals, especially their modality. This renders mathematical models of signal evolution applicable across taxa and modalities (Box 3). Critics object, however, that abstracting away from the physical structures has contributed to a neglect of research into signal production and design (Owings \& Morton, 1997; Rendall et al., 2009).

A good heuristic

For decades the informational framework has driven behavioural research on animal communication. It proves to be a fruitful strategy in other fields as well (Seyfarth et al., 2010). With respect to the study of human language evolution, for instance, the framework has elucidated language evolution

\section{Box 4 Animal signals and human language}

Is animal signalling a kind of language? What is the relation between signalling systems and human language more generally? For a long time language was regarded as the gap separating humans from other animals. Of course, other animals lack a language insofar as they do not share any of our culturally specific communication systems (English, Chinese and so on). But 'language' also refers to the internal (neural and psychological) faculty that allows humans to learn and employ such systems (Hauser, Chomsky \& Fitch, 2002). And with respect to that faculty a nuanced view about the relation between animal signals and human language has emerged. Following the linguist David Hockett, many contemporary theorists 
Table 2 Some components of the human language faculty and their presence in nonhuman animals.

\begin{tabular}{ll}
\hline \hline Humans (Fitch, 2010) & Non-human animals \\
\hline $\begin{array}{l}\text { Ability to learn the production of } \\
\text { large vocabulary }\end{array}$ & Absent (Fitch, 2010; Fedurek \& Slocombe, 2011) \\
$\begin{array}{l}\text { Voluntary signal production } \\
\text { Mostly absent, but some species have degrees of } \\
\text { control over signal production (e.g. audience effect) } \\
\text { (Seyfarth \& Cheney, 2003; Fedurek \& Slocombe, }\end{array}$ & $\begin{array}{l}\text { 2011) } \\
\text { Absent (Hauser et al., 2002) }\end{array}$ \\
$\begin{array}{l}\text { Discrete infinity }{ }^{a} \text { /recursion } \\
\text { Reference (providing information } \\
\text { about external states) }\end{array}$ & $\begin{array}{l}\text { Present in some species (Cheney \& Seyfarth, 2007) } \\
\text { Senders intend to provide } \\
\text { information (Gricean maxims) }\end{array}$ \\
$\begin{array}{l}\text { Theory of mind (attributing mental } \\
\text { states to others) }\end{array}$ & $\begin{array}{c}\text { No attribution of beliefs; in some species attribution } \\
\text { of intentions, goals and visual experience (Rosati }\end{array}$ \\
Listeners engage in pragmatic & Present (Seyfarth \& Cheney, 2003; Fitch, 2010) \\
inferences & \\
\hline \hline
\end{tabular}

${ }^{a}$ Discrete infinity is the ability to construct and understand an infinite number of linguistic expressions where the expressions are composed from a finite set of components.

advocate a multi-component view of the language faculty: language is composed of several partly independent subsystems with their own functions and neural implementations (e.g. Hauser et al., 2002; Christiansen \& Kirby, 2003; Hurford, 2007; Fitch, 2010). A select few of these components are listed in Table 2 . Only some of the components are found in non-human animal species, and some are at the centre of controversies. For instance, Hauser et al.'s (2002) hypothesis that recursion (the ability to understand and produce recursive structures, such as embedded clauses) is the uniquely human language component reinvigorated interest in syntactic features of animal signals (e.g. Arnold \& Zuberbühler, 2006; Gentner et al., 2006; Van Heijningen et al., 2009; Wheeler et al., 2011).

Are animal signals evolutionary precursors of human language? It has been argued that at least some features of primate vocalisations are precursors of linguistic abilities, e.g. functional reference and the ordering of call types into sequences (Fedurek \& Slocombe, 2011). According to an early view, language evolved from innate affective expressions such as sighs and screams, which were regarded as similar to 
animal signals. This idea is mostly rejected nowadays (Fitch, 2010; but see Bar-On \& Green, 2010). Most contemporary theories of language evolution are concerned with the evolution of our 'proto-language', i.e. with the order in which the various components of our language faculty evolved in the hominid lineage that descended from our last common ancestor with chimpanzees (including its initial modality). The theories fall into three broad groups, proposing lexical, gestural and musical proto-languages, respectively (reviewed in Fitch, 2010; Wheeler et al., 2011). Some theorists emphasise the extent to which the evolution of human language (as communication systems) depended on prior conditions, such as social interactions, context of use and capabilities like a theory of mind (Sperber \& Origgi, 2010). (The relation between animal signalling and human language is further explored in Chapters 17 and 18.)

by identifying a number of striking similarities to and differences from nonhuman primate vocalisations (Fedurek \& Slocombe, 2011; see also Box 4 and Chapters 17 and 18). Some of the similarities and differences concern the neural basis of language production and processing (Ch. 14). Such questions have in turn inspired research in primate neurophysiology (e.g. Platt \& Ghazanfar, 2010).

Arguments against information

The classic objection against information concerns evolution: given how selection operates, signals simply could not evolve in order to convey information (Box 3). This objection was subsequently refuted. But new concerns took its place. Here I mention two lines of argument.

Problems surrounding the core concepts

One line of argument is that central concepts such as information are poorly understood and mired in difficulties. Often information is defined vaguely or not at all (Rendall et al., 2009), and consequently it is unclear how something so vague and abstract can be reconciled with causal concepts like function and mechanism (Owren \& Rendall, 2001). A related worry is that informational concepts are merely metaphors. For instance, 'information transfer' evokes some kind of concrete entity which senders hand over to receivers like a parcel; but there is no such thing, of course (Owren \& Rendall, 2001; Rendall et al., 2009). It is worth noting that proponents of information have acknowledged difficulties with their key concepts but regarded them as solvable 
(e.g. Burghardt, 1970; Markl, 1985; Hasson, 1994; Dawkins, 1995; Maynard Smith \& Harper, 1995; Philips \& Austad, 1996; Evans, 1997; Seyfarth et al., 2010).

A bad heuristic

As a specifically linguistic metaphor (Owren \& Rendall, 2001; Owren et al., 2010), information is anthropomorphic (Owings \& Morton, 1997) and strongly biases our perspective on animal communication (Rendall et al., 2009): the informational view highlights whatever is similar to human language and neglects the rest. For example, our understanding of signal processing is skewed in favour of cognitive mechanisms (Owings \& Morton, 1997; Owren \& Rendall, 1997), especially in favour of cortical processing of the sort familiar from conceptual representation and language comprehension in humans (Owren \& Rendall, 2001). The significance of non-cortical signal processing is downplayed (e.g. motivational effects in songbirds; see 'Assessment/ management' above). Seyfarth et al. (2010) reject these criticisms. Information, they argue, is a non-linguistic concept, simply referring to the idea that the correlations between signals and conditions enable predictions (see 'Colloquial information'). Furthermore, information has not biased our view because, for instance, it underpinned the discovery of dissimilarities between human and non-human primate vocalisations (Box 4).

The chapters in this volume explore these and other arguments both in favour of information (Chapters 1, 2, 4, 11-13, 15-17) and against it (Chapters 6-9). But it is time to consider arguments surrounding manipulation.

\section{Arguments concerning manipulation}

The overall argument advanced in favour of influence views is that they do not suffer the difficulties of informational approaches. In particular, explanations in terms of manipulation are thought to be neither metaphoric nor biased against non-cognitive signal processing (e.g. Owings \& Morton, 1998; Rendall et al., 2009). But influence models have seen their share of criticism. The following two difficulties stand out.

The rarity of direct impact

The affect induction model predicts that many primate calls have a direct impact on conserved, subcortical systems (see 'Affect induction' above). Therefore, calls with similar acoustic properties should elicit similar reactions, whereas calls with different properties should not. But neither prediction is well supported (Seyfarth et al., 2010). First, calls with similar acoustic properties can often elicit different reactions depending on context. For instance, vervets hearing an eagle alarm call run into bushes; but if they are already there, they 
usually do not show any overt behavioural response (Seyfarth et al., 1980). Second, vocalisations with very different acoustic properties can nonetheless elicit the same response (Box 2).

Inconsistency with evolutionary theory

Manipulation is often interpreted as implying a disadvantage to receivers (see 'Manipulation and influence' above). Disadvantaged receivers will be selected to decrease their responsiveness to manipulative signals until they ignore them. At that point senders cease to benefit from signalling (Box 3). Senders will then be selected for reducing their signalling costs, until eventually the signalling system disappears altogether (Searcy \& Nowicki, 2005). But signal systems are ubiquitous, so the influence model must be wrong (Seyfarth et al., 2010). Defenders of manipulation theories concede that receivers will evolve defence mechanisms against manipulation. But they argue that, owing to tradeoffs and the dynamics of arms races, counter-selection need not always lead to the elimination of signalling systems (Rendall et al., 2009; but see Bradbury \& Vehrencamp, 2011b).

This section has sketched some of the major lines of conflict in the debate about informational and non-informational approaches to animal communication. We have seen that both sides have advanced powerful arguments. This may explain why the two approaches are sometimes seen as complementary rather than incompatible (e.g. Krebs \& Dawkins, 1984; Owings \& Morton, 1998; Carazo \& Font, 2010). The following section moves beyond the to-and-fro within animal communication studies. It takes a broader and more abstract look at key concepts of the information view, some of which come with heavy philosophical baggage. Unpacking some of the baggage, if ever so cursorily, can shed light on theoretical commitments and opportunities.

\section{Philosophical perspectives}

Scientific realism

We can bring the information debate into sharper focus by situating it in the wider debate about scientific realism. Local scientific realists hold that at least some of our best scientific theories are (approximately) true and that some of their central terms refer to things in the world. At first blush, the claim that signals convey information is a local realist claim about a specific theoretical entity, information. It seems to imply that there is something in the world to which 'conveying information' refers, for example a capacity to enable predictions, and that signals do in fact have this capacity. By contrast, the 
claim that information is a metaphor denies that the word 'information' picks out anything in the world. The metaphor view is thus an anti-realist position about information.

However, informational views are not committed to realism about information. Proponents of information sometimes emphasise the heuristic value of concepts such as information and mental states while remaining neutral about any mechanistic implications (certain passages in Cheney and Seyfarth,1990, and Seyfarth and Cheney, 2003). This approach echoes Dennett's (1983) 'intentional stance'. The intentional stance recommends attributing mental states (goals, beliefs, desires) to animals in order to explain and predict their behaviour. It involves no assumptions about the internal, neural structure of these states; it does not even presuppose that animals possess any belief- or desire-like states at all. Treating animals as if they possessed mental states is justified simply to the extent that such practices increase explanatory and predictive power. By analogy, an 'informational stance' would recommend attributing information to signals in order to explain and predict behaviour without assuming anything about the nature or existence of information. The intentional (and informational) stance regards scientific and theoretical concepts primarily as tools for explanation. This is a form of instrumentalism, and adopting this version of instrumentalism with respect to information radically changes how we ought to assess informational claims. Rather than asking whether it is true that signals carry information we should ask whether such a claim is useful. However, this approach to information would still be vulnerable against arguments targeting its heuristic value (cf. Barret \& Rendall, 2010).

\section{A family of information concepts}

Attempts to define the key notions of the informational view are sometimes dismissed as semantic squabbles. The point of definitions sometimes is semantic, e.g. when attempting to fix the meaning of a word like 'communication'. And disputes about which term to use for a given phenomenon can indeed be fruitless (although unifying language use can reduce misunderstandings). But sometimes it is not so clear what sorts of phenomena there are in the first place, and then definitions can be an important means of tracking distinguishing features (Maynard Smith \& Harper, 2003). For instance, the goal of distinguishing between "cost-added signals" and "indices" was not to regiment language use, but to acknowledge that signals can differ markedly in the evolutionary mechanisms securing their reliability (Maynard Smith \& Harper, 2003). 
In philosophical jargon, definitions that aim to identify the key features of some phenomenon $X$ are usually called 'theories of $X$ ' or 'accounts of $X$ '. Philosophers have developed numerous theories of phenomena such as communication, information, representation, meaning and reference. This section sketches some of the insights most relevant to animal communication (although it can do no more than scratch the surface).

\section{Information}

For many philosophers, information is simply a relation between two facts or events, something requiring no receivers, no minds, cognition or knowledge. Dretske (1981) was among the first to suggest that information is an 'objective commodity', a mind-independent relation in the world. He held that some state or event $A$ carries the information that another state or event $B$ obtains if there is a probabilistic relation between them, i.e. if $A$ makes $B$ certain (specifically, if A's occurrence increases the probability of $B$ 's occurrence to 1 , and if that probability is less than 1 otherwise). One of the most attractive features of Dretske's theory is that information consists in a non-mysterious, probabilistic relation between states (it is 'naturalistic'). One of the arguably less attractive features is that it requires $A$ to raise $B$ 's probability to 1 : which events are ever so tightly linked? Several philosophers have therefore turned to weaker notions of information (e.g. Millikan, 2004; Shea, 2007; Scarantino \& Piccinini, 2010; see also Chapters 2 and 5).

\section{Representation}

Philosophers usually distinguish sharply between information and representation. Carrying information about $B$ implies that $B$ exists (see above); whereas representing something as being $B$ does not imply that it is $B$. Consider the philosophers' paradigm of representational entities, beliefs and desires. My belief that the sky is blue is a mental state that represents the sky as being blue (i.e. that the sky is blue is the belief's representational content). My belief may be false; just believing the sky is blue does not make it so. Hence, mental states can be about states that may or may not obtain (or be about things that may or may not exist). This remarkable property of mental states of being directed at things is also known as intentionality ${ }^{2}$ and has nothing to do with having intentions (for related issues see Box 5).

\footnotetext{
${ }^{2}$ Intentionality (with a ' $t$ ') must be distinguished from intensionality (with an 's'). The former is a property of mental states, i.e. their 'aboutness'. The latter is a property of languages rather than mental states, and it is defined in terms of certain inferential principles (see also Box 5).
} 


\section{Box 5 Referential opacity and indeterminacy of translation}

Referential opacity and indeterminacy of translation are two philosophical ideas which must be mentioned because they have made their way into the ethological literature. But their value for ethology is doubtful.

\section{Referential opacity}

Suppose the statement "Susan believes that Bob Dylan is a musician" is true (i.e. she believes Dylan is a musician); now replace 'Bob Dylan' with his birth name 'Robert Allen Zimmerman'. The new sentence "Susan believes that Robert Allen Zimmerman is a musician" may well be false, for example if Susan does not know that both names refer to the same man. A sentence is said to create a 'referentially opaque' context for an expression if one can change the sentence's truth value by replacing the expression with a different term that refers to the same thing. Sentences about mental states such as beliefs and desires are referentially opaque. For this reason, referential opacity (or the broader notion of intensionality; see footnote 2 ) is sometimes taken to indicate the presence of intentionality (e.g. Chisholm, 1957; Dennett, 1983). But this is highly controversial (e.g. Allen, 1995; Crane, 2001).

\section{Indeterminacy of translation}

An anthropologist tries to translate into English the words of a newly discovered tribe. Quine (1960) argued that the difficulties in translating, say, 'gavagai' as 'rabbit' show that there is no fact of the matter about which translation is correct; indeed, there is no fact of the matter about what 'gavagai' means, or even 'rabbit'. Quine's point is much more radical than usually interpreted: it is not that identifying word meanings is difficult (cf. Hauser, 1996; Cheney \& Seyfarth, 2007), but rather that words lack (determinate) meanings. Quine's meaning scepticism is now widely rejected (reviewed in Miller, 2006).

Some philosophers maintain that intentionality and representational content consist in physical and biological relations that are as non-mysterious as the relations constituting information. Dretske (1988) argued, for instance, that any state or event $A$ represents a state or event $B$ if $A$ has the biological 
function to carry the information that B obtains. Dretske's proposal is relevant for present purposes because it implies that representational content is not the privilege of mental states alone: animal signals have representational content simply by virtue of having evolved in order to carry information; receivers do not need to mentally represent referents. Talk of 'false' animal signals is then not metaphoric, but expresses the idea that signals can represent what does not exist (but see Ch. 17). More recent accounts of representation deviate in various ways from Dretske's proposal, but accept that animal signals can represent states and events (e.g. Millikan, 1984, 2004; Bekoff \& Allen, 1992; Stegmann, 2009).

Communication

On the informational view, animal communication involves conveying information from senders to receivers. The cognitively most demanding view of conveying information requires signals to elicit mental representations in receivers (see ‘Colloquial information' above). But even this considerable degree of cognitive complexity pales in comparison with the complexity normally associated with human communication.

The orthodox view of human communication is due to Grice (but see Millikan, 1984; Green, 2007). For Grice, speakers communicate when they utter sentences with certain "communicative intentions" (reviewed in Neale, 1992). The simplest of these intentions is that listeners believe that $p$ (where $p$ is the proposition the speaker intends to communicate, e.g. "the tree is green"). In order to meet even this basic condition of communication, speakers need to have at least one kind of mental state: intentions. More importantly, they need to be able to attribute to listeners the belief that $p$. Gricean communication requires still more complex mental state attributions, e.g. that listeners recognise that the speaker intends them to believe that $p$. Despite decades of research, there is little evidence that non-human primates attribute even simple beliefs, let alone false ones, to others (Cheney \& Seyfarth, 2007; Rosati et al., 2010). To the contrary, there is evidence that primates fail to reason about the beliefs of others (although some species attribute mental states such as intentions, goals and visual experience and therefore have a 'theory of mind' of sorts, reviewed in Rosati, Santos \& Hare, 2010).

\section{Meaning}

What speakers communicate is what they intend to convey by uttering a sentence. But the sentences employed to convey the intended meaning possess their own conventional or linguistic meanings, i.e. meanings which are independent of what speakers intend to convey by uttering the sentences. Perhaps 
the most influential theory of linguistic meaning holds that a sentence's meaning is its truth condition (e.g. Davidson, 1967). On this view, the meaning of the sentence "the tree is green" is the state of the world that makes this sentence true: the fact that the tree is green.

Critics of information concepts allege that comparing animal signals with human words is bound to skew our explanations of behaviour in terms of linguistic meaning analogues. But comparisons with human language can also include pragmatic aspects of communication. Horn (1997) suggested, for instance, that animal signals are analogous to speech acts. Speech acts are actions performed by uttering sentences, and they are effective primarily because of social rules, not because of the linguistic meaning attached to the sentences we utter (Austin, 1962). Note that there are other approaches in philosophy of language that minimise the role of linguistic meanings and that have been applied to animal signals (McAninsh et al., 2009; Bar-On \& Green, 2010).

\section{Reference}

Names and general terms pick out (or refer to) particular individuals and kinds of things, respectively (e.g. 'Simon' picks out Simon, 'water' picks out water). Much philosophical work has focused on understanding the mechanism that secures the link between a term and what it picks out: why does 'water' refer to water rather than something else, and why does it pick out anything at all? The traditional answer points to the minds of speakers and listeners. A term like 'water' is associated with descriptions (or a set of concepts) that speakers have in their minds, for example "- is composed of $\mathrm{H}_{2} \mathrm{O}$ molecules" or “-is transparent". The term 'water' refers to a particular body of fluid on the condition that this fluid exactly matches the descriptions. Ogden and Richards' (1923) "triangle of meaning" illustrates the descriptivist approach, which remains popular in the cognitive sciences. Crucially, descriptivism underlies much reasoning about referential signals: signals count as referential in a strong, word-like sense only if they elicit mental representations (see 'Colloquial information' above).

However, descriptivism in its classical form has been discredited in philosophy of language. Kripke (1980) and Putnam (1975) argued that reference depends on a term bearing the right kind of causal connection to a thing, not on the associations or concepts that a term evokes in speakers and in hearers. The causal-historical approach has its own problems. But the negative point, that reference is not determined by what speakers and hearers have in their minds ('semantic externalism'), is well supported. 


\section{Outlook}

Perhaps the most obvious conclusion from this survey is that the suitability of information and/or manipulation for explaining animal communication is not simply an empirical matter. It also depends on which notions of information and manipulation one endorses.

Critics of information deserve credit for insisting that information concepts are still poorly understood. Several distinct notions of colloquial information are in use (a fact which largely has gone unnoticed), and it is unclear how they relate to one another. Moreover, each notion raises further questions which are seldom addressed rigorously: for example, on the view that carrying information consists in allowing predictions, should non-cognitive processes count as predictions? Furthermore, mathematical models of signal evolution use an information concept that appears to be distinct from the one used in applications of statistical decision theory (reliability versus changes to estimates of probability), and again it is unclear how they interrelate. However, in my view it is premature to conclude from these gaps that information concepts are inappropriate. First, it is not obvious that the gaps need to be filled, because tools such as statistical decision theory have proven fruitful without a unified, clearcut concept of information. Second, it is likely that the gaps can be filled eventually, e.g. by integrating philosophical research on information concepts.

The concept of manipulation faces similar challenges. The costs-to-receivers interpretation, on which the opponents of manipulation have focused almost exclusively, should be more clearly distinguished from proximate interpretations. One proximate interpretation is that signals manipulate when receivers process signals by non-cognitive mechanisms. Since signals can affect receivers through either cognitive or non-cognitive mechanisms (or both, depending on the species), manipulation should play a role in any comprehensive account of signal processing. As far as I can see, this is the strongest argument for the importance of manipulation. And it should carry some weight with those who identify informational communication with a certain type of proximate mechanism of signal processing by receivers (i.e. a mechanism involving representations of referents). Such a proximate interpretation exacts its price, however. It ignores the uses of information in, for instance, evolutionary models; it undermines any outright rejection of information, because some receivers do process signals cognitively (and, hence, informationally); and it seems to requires a firm distinction between cognitive and non-cognitive mechanisms of signal processing.

I wish to resist characterising information in proximate terms. I believe that the informational approach is valuable, not because it captures a kind of proximate mechanism of signal processing, but because it provides ultimate 
(etiological) explanations of receiver responses (Stegmann, 2005, 2009). Let us return to the fireflies. The disposition of male fireflies to approach certain light pulses is explained, on the informational approach, by the signal's information that there is a receptive female. The presence of a receptive female at the source of a certain light pulse is, plausibly, the reason why males were selected to approach the light source. In other words, the information content of the light pulses specifies the reason by virtue of which males acquired their response dispositions over evolutionary time. This idea can be generalised as follows. Asserting that a receiver responds with $R$ to a signal because (1) the signal carries the information that $p$ is another way of saying that the receiver responds with $R$ because $\left(1^{*}\right) p$ caused receivers to evolve/learn the disposition to do $R$. In other words, citing the information content $p$ explains $R$ by identifying the reason that caused receivers to evolve/learn the $R$-disposition in the first place. The information content therefore provides an ultimate explanation of $R$. The approach just sketched is compatible with requiring that full explanations of $R$ ought to include R's proximate mechanisms, as well. However, whether or not the mechanisms involve mental representations would be irrelevant to whether or not the signal carries information.

\section{Acknowledgements}

I am very grateful to Jack Bradbury, Andrew Horn and Robert Seyfarth for their feedback on the draft version. Richard Coss, Joel McGlothlin, Michael Ryan, Robert Seyfarth, Ron Swaisgood, Richard Wrangham and Klaus Zuberbühler were enormously helpful in providing drawings, diagrams and photographs. I thank Bartolomeu Bastos for being such a reliable and efficient research assistant. The work in preparation for this introduction was generously supported by two grants from the British Academy (PDF/2006/306 and SG-51996).

\section{References}

Allen, C. (1995). Intentionality: natural and artificial. In H. L. Roitblat \& J. Meyer, eds., Comparative Approaches to Cognitive Science. Cambridge, MA: MIT Press, pp. 93-110.

Apfelbeck, B. \& Goymann, W. (2011). Ignoring the challenge? Male black redstarts (Phoenicurus ochruros) do not increase testosterone levels during territorial conflicts but they do so in response to gonadotropin-releasing hormone. Proceedings of the Royal Society of London Series B: Biological Sciences, 278, 3233.

Arnold, K. \& Zuberbühler, K. (2006). Language evolution: Semantic combinations in primate calls. Nature, 106, 303-303. 
Austin, J. L. (1962). How to Do Things with Words, 2nd edn. Cambridge, MA: Harvard University Press.

Bar-On, D. \& Green, M. (2010). Lionspeak: communication, expression and meaning. In J. O'Shea \& E. Rubenstein, eds., Self, Language, and World: Problems from Kant, Sellars, and Rosenberg: in Memory of Jay F. Rosenberg. Atascadero, CA: Ridgeview Publishing Co.

Barret, L. \& Rendall, D. (2010). Out of our minds: the neuroethology of primate strategic behavior. In M. L. Platt \& A. A. Ghazanfar, eds., Primate Neuroethology. Oxford: Oxford University Press.

Bekoff, M. \& Allen, C. (1992). Intentional icons: towards an evolutionary cognitive ethology. Ethology, 91, 1-16.

Bergstrom, C.T. \& Rosvall, M. (2011). The transmission sense of information. Biology and Philosophy, 26, 159-176.

Bradbury, J. W. \& Vehrencamp, S. L. (2011a). Principles of Animal Communication, 2nd edn. Sunderland, MA: Sinauer Associates.

Bradbury, J.W. \& Vehrencamp, S. L. (2011b). Web Topic 1.2: Information and Communication. Principles of Animal Communication, 2nd edn companion website. http://sites.sinauer.com/animalcommunication2e

Bradbury, J. W. \& Vehrencamp, S. L. (2011c). Web Topic 8.7: Brains and Decision Making. Principles of Animal Communication, 2nd edn companion website. http://sites. sinauer.com/animalcommunication2e

Burghardt, G. M. (1970). Defining 'communication'. In J. W. Johnston, D. G. Moulton \& A. Turk, eds., Communication by Chemical Signals. New York: Appleton-Century Crofts, pp. 5-18.

Carazo, P. \& Font, E. (2010). Putting information back into biological communication. Journal of Evolutionary Biology, 23, 661-669.

Cheney, D. L. \& Seyfarth, R. M. (1990). How Monkeys See the World. Chicago, IL: University of Chicago Press.

Cheney, D. L. \& Seyfarth, R. M. (2007). Baboon Metaphysics. Chicago, IL: University of Chicago Press.

Chisholm, R. (1957). Perceiving: A Philosophical Study. Ithaca, NY: Cornell University Press. Christiansen, M. \& Kirby, S. (2003). Language Evolution. Oxford: Oxford University Press. Clutton-Brock, T. \& Albon, S. D. (1979). The roaring of red deer and the evolution of honest advertisement. Behaviour, 69, 145-170.

Crane, T. (2001). Elements of Mind: An Introduction to the Philosophy of Mind. Oxford: Oxford University Press.

Danchin, E., Giraldeau, L. A., Valone, T. J. \& Wagner, R. H. (2004). Public information: from nosy neighbors to cultural evolution. Science, 305(5683), 487-491.

Davidson, D. (1967). Truth and meaning. Synthese, 17, 304-323.

Dawkins, M. S. (1995). Unravelling Animal Behaviour. Harlow: Longman.

Dawkins, R. \& Krebs, J. R. (1978). Animal signals: information or manipulation. In J. R. Krebs \& N. B. Davies, eds., Behavioural Ecology: An Evolutionary Approach, 1st edn. Oxford: Blackwell, pp. 282-309.

Dennett, D. C. (1983). Intentional systems in cognitive ethology: the 'Panglossian Paradigm' defended. Behavioral and Brain Sciences, 6, 343-390. 
Dingle, H. (1969). A statistical and information analysis of aggressive communication in the mantis shrimp Gonodactylus bredini Manning (Crustacea: Stomatopoda). Animal Behaviour, 17, 567-581.

Dretske, F. (1981). Knowledge and the Flow of Information. Cambridge, MA: MIT Press.

Dretske, F. (1988). Explaining Behavior: Reasons in a World of Causes. Cambridge, MA: MIT Press.

Dyer, F. C. (2002). The biology of the dance language. Annual Review of Entomology, 47, 917-949.

Evans, C. S. (1997). Referential signals. In D. H. Owings, M. D. Beecher \& N. Thompson, eds., Communication. Perspectives in Ecology, Vol. 12. New York: Plenum Press, pp. 99-143.

Evans, C. S. \& Evans, L. (1999). Chicken food calls are functionally referential. Animal Behaviour, 58, 307-319.

Evans, C. S. \& Evans, L. (2007). Representational signalling in birds. Biology Letters, 3, 8-11.

Fedurek, P. \& Slocombe, K. E. (2011). Primate vocal communication: a useful tool for understanding human speech and language evolution? Human Biology, 82, 153-173.

Fischer, J., Hammerschmidt, K. \& Todt, D. (1995). Factors affecting acoustic variation in Barbary macaque (Macaca sylvanus) disturbance calls. Ethology, 101, 51-66.

Fitch, W. T. (2010). The Evolution of Language. Cambridge: Cambridge University Press.

Font, E. \& Carazo, P. (2010). Animals in translation: why there is meaning (but probably no message) in animal communication. Animal Behaviour, 80, e1-e6.

Gallistel, C. R. (2008). Learning and representation. In R. Menzel, ed., Learning Theory and Behavior. Learning and Memory: A Comprehensive Reference, Vol. 1. Oxford: Elsevier, pp. 227-242.

Gentner, T. Q., Fenn, K. M., Margoliash, D. \& Nusbaum, H. C. (2006). Recursive syntactic pattern learning by songbirds. Nature, 440, 1204-1207.

Gil-da-Costa, R., Braun, A., Lopes, M. et al. (2004). Towards an evolutionary perspective on conceptual representation: species-specific calls activate visual and affective processing systems in the macaque. Proceedings of the National Academy of Sciences, Biological Sciences (Neurosciences), 101, 50.

Giraldeau, L. A. (1997). The ecology of information use. In J. R. Krebs \& N. B. Davies, eds., Behavioural Ecology: An Evolutionary Approach. Oxford: Blackwell, pp. 42-68.

Green, M. (2007). Self-expression. Oxford: Oxford University Press.

Halliday, T. (1983). Information and communication. In T. Halliday \& P. J. B. Slater, eds., Communication. Animal Behaviour, Vol. 2. Oxford: Blackwell Scientific, pp. 43-81.

Hasson, O. (1994). Cheating signals. Journal of Theoretical Biology, 167, 223-238.

Hauser, M. D. (1996). The Evolution of Communication. Cambridge, MA: MIT Press.

Hauser, M. D. (1998). Functional referents and acoustic similarity: field playback experiments with rhesus monkeys. Animal Behaviour, 55, 1647-1658.

Hauser, M. D., Chomsky, N. \& Fitch, W.T. (2002). The faculty of language: what is it, who has it, and how did it evolve? Science, 298, 1569-1579. 
Hazlett, B. A. \& Bossert, W. H. (1965). A statistical analysis of the aggressive communications systems of some hermit crabs. Animal Behaviour, 13, 357-373.

Horn, A. G. (1997). Speech acts and animal signals. In D. H. Owings, M. D. Beecher \& N. S. Thompson, eds., Communication. Perspectives in Ethology, Vol. 12. New York: Plenum Press,

Hurford, J. (2007). The Origins of Meaning. Oxford: Oxford University Press.

Johnstone, R. A. (1997). The evolution of animal signals. In J. R. Krebs \& N. B. Davies, eds., Behavioural Ecology: An Evolutionary Approach, 4th edn. Oxford: Blackwell, pp. $155-178$.

Kirkpatrick, M. \& Ryan, M. J. (1991). The evolution of mating preferences and the paradox of the lek. Nature, 350, 33-38.

Krebs, J. R. \& Davies, N. B. (1993). An Introduction to Behavioural Ecology. Oxford: Blackwell Scientific Publications.

Krebs, J. R. \& Dawkins, R. (1984). Animal signals: mind-reading and manipulation. In J. R. Krebs \& N. B. Davies, eds., Behavioural Ecology: An Evolutionary Approach, 2nd edn. Oxford: Blackwell, pp. 380-402.

Kripke, S. (1980). Naming and Necessity. Cambridge, MA: Harvard University Press.

Laidre, M. E. (2009). How often do animals lie about their intentions? An experimental test. American Naturalist, 173, 337-346.

Lee, D. (2010). Neuroethology of decision making. In M. L. Platt \& A. A. Ghazanfar, eds., Primate Neuroethology. New York: Oxford University Press, pp. 550-569.

Lewis, S. M. \& Cratsley, C. K. (2008). Flash signal evolution, mate choice, and predation in fireflies. Annual Review of Entomology, 53, 293-321.

Lieberman, D. A. (2003). Learning and Memory: An Integrative Approach. New York: Wadsworth Publishing.

Lloyd, J. E. (1966). Studies on the flash communication system in Photinus fireflies. Miscellaneous Publications, Museum of Zoology, University of Michigan, 130, 1-95.

Macedonia, J. M. \& Evans, C. S. (1993). Variation among mammalian alrm call systems and the problem of meaning in animal signals. Ethology, 93, 177-197.

Manser, M. B., Bell, M. B. \& Fletcher, L. B. (2001). The information that receivers extract from alarm calls in suricates. Proceedings of the Royal Society of London Series B: Biological Sciences, 268, 2485-2491.

Markl, H. (1985). Manipulation, modulation, information, cognition: some of the riddles of communication. In B. Hölldobler \& M. Lindauer, eds., Experimental Behavioral Ecology and Sociobiology. Stuttgart: G. Fischer Verlag, pp. 163-194.

Marler, P. (1961). The logical analysis of animal communication. Journal of Theoretical Biology, 7, 295-317.

Marler, P., Evans, C. S. \& Hauser, M. D. (1992). Animal signals? Reference, motivation or both? In H. Papoucek, U. Jürgens \& M. Papoucek, eds., Nonverbal Vocal Communication: Comparative and Developmental Approaches. Cambridge: Cambridge University Press, pp. 66-86.

Maynard Smith, J. (1976). Sexual selection and the handicap principle. Journal of Theoretical Biology, 57, 239-242. 
Maynard Smith, J. \& Harper, D. G. C. (1995). Animal signals: models and terminology. Journal of Theoretical Biology, 177(3), 305-311.

Maynard Smith, J. \& Harper, D. (2003). Animal Signals. Oxford: Oxford University Press.

McAninsh, A., Goodrich, G. \& Allen, C. (2009). Animal communication and neoexpressivism. In R. W. Lurz, ed., Philosophy of Animal Minds: New Essays on Animal Thought and Conciousness. Cambridge: Cambridge University Press, pp. 128-144.

McGlothlin, J. W., Jawor, J. M., Greives, T. J., Phillips, J. L. \& Ketterson, E. D. (2008). Hormones and honest signals: males with larger ornaments elevate testosterone more when challenged. Journal of Evolutionary Biology, 21, 39-48.

McGregor, P. K. (1993). Signalling in territorial systems: a context for individual identification, ranging and eavesdropping. Philosophical Transactions of the Royal Society of London Series B, 340, 237-244.

McNamara, J. M. \& Dall, S. R. X. (2010). Information is a fitness enhancing resource. Oikos, 119(2), 231-236.

Miller, A. (2006). Meaning scepticism. In M. Devitt \& R. Hanley, eds., The Blackwell Guide to the Philosophy of Language. Oxford: Blackwell, pp. 91-113.

Millikan, R. G. (1984). Language, Thought and Other Biological Categories. Cambridge, MA: MIT Press.

Millikan, R. G. (2004). The Varieties of Meaning. Cambridge, MA: MIT Press.

Munz, T. (2005). The bee battles: Karl von Frisch, Adrian Wenner and the honey bee dance language controversy. Journal of the History of Biology, 38(3), 535-570.

Neale, S. (1992). Paul Grice and the philosophy of language. Linguistics and Philosophy, 15(5), 509-559.

Ogden, C. K. \& Richard, I. A. (1923). The Meaning of Meaning: A Study of the Influence of Language upon Thought and of the Science of Symbolism, 8th edn. New York: Harcourt, Brace \&; World, Inc.

Otte, D. (1974). Effects and functions in the evolution of signaling systems. Annual Review of Ecology and Systematics, 5, 385-417.

Owings, D. H. \& Morton, E. S. (1997). The role of information and communication: an assessment/management approach. In D. H. Owings, M. D. Beecher \& N. S. Thompson, eds., Communication. Perspectives in Ecology, Vol. 12. New York: Plenum Press, pp. 359-390.

Owings, D. H. \& Morton, E. S. (1998). Animal Vocal Communication: A New Approach. Cambridge: Cambridge University Press.

Owren, M. J. \& Rendall, D. (1997). An affect-conditioning model of non-human primate vocal signaling. In D. H. Owings, M. D. Beecher \& N. S. Thompson, eds., Communication. Perspectives in Ethology, Vol. 12. New York: Plenum Press, pp. 299-346.

Owren, M.J. \& Rendall, D. (2001). Sound on the rebound: bringing form and function back to the forefront in understanding non-human primate vocal signaling. Evolutionary Anthropology, 10, 58-71.

Owren, M. J., Rendall, D. \& Ryan, M. J. (2010). Redefining animal signaling: influence versus information in communication. Biology and Philosophy, 25, 755-780. 
Philips, M. \& Austad, S. N. (1996). Animal communication and social evolution. In M. Bekoff \& D. Jamieson, eds., Readings in Animal Cognition. Cambridge, MA: MIT Press, pp. 257-267.

Platt, M. L. \& Ghazanfar, A. A. (eds.) (2010). Primate Neuroethology. Oxford: Oxford University Press.

Putnam, H. (1975). The meaning of 'meaning'. In K. Gunderson, ed., Language, Mind, and Knowledge. Minnesota Studies in the Philosophy of Science, Vol. 8. Minneapolis, MN: University of Minnesota Press, pp. 131-193.

Quastler, H. (1958). A primer on information theory. In H. P. Yockey, R. L. Platzman \& H. Quastler, eds., Symposium on Information Theory in Biology. Gatlinburg, Tennessee, October 29-31, 1956. London: Pergamon Press, pp. 3-49.

Quine, W.V.O. (1960). Word and Object. Cambridge, MA: MIT Press.

Radick, G. (2007). The Simian Tongue: The Long Debate about Animal Language. Chicago, IL: University of Chicago Press.

Reby, D., McComb, K., Cargnelutti, B. et al. (2005). Red deer stags use formants as assessment cues during intrasexual agonistic interactions. Proceedings of the Royal Society of London Series B: Biological Sciences, 272, 941-947.

Rendall, D., Owren, M. J. \& Ryan, M. J. (2009). What do animal signals mean? Animal Behaviour, 78(2), 233-240.

Romanski, L. M. \& Ghazanfar, A.A. (2010). The primate frontal and temporal lobes and their role in multisensory vocal communication. In M. L. Platt \& A. A. Ghazanfar, eds., Primate Neuroethology. Oxford: Oxford University Press, pp. 500-524.

Ron, S. R. (2008). The evolution of female mate choice for complex calls in túngara frogs. Animal Behaviour, 76, 1783-1794.

Rosati, A. G., Santos, L. R. \& Hare, B. (2010). Primate social cognition: thirty years after Premack and Woodruff. In M. L. Platt \& A. A. Ghazanfar, eds., Primate Neuroethology. Oxford: Oxford University Press.

Rowe, M. P. \& Owings, D. H. (1990). Probing, assessment, and management during interactions between ground squirrels and rattlesnakes. Ethology, 86(3), 237-249.

Ruxton, G. D. \& Schaefer, H. M. (2011). Resolving current disagreements and ambiguities in the terminology of animal communication. Journal of Evolutionary Biology, 24(12), 2574-2585.

Ryan, M. J. \& Rand, A. S. (2003). Mate recognition in túngara frogs: a review of some studies of brain, behavior, and evolution. Acta Zoologica Sinica, 49, 713-726.

Scarantino, A. (2010). Animal communication between information and influence. Animal Behaviour, 79(6), e1-e5.

Scarantino, A. \& Piccinini, G. (2010). Information without truth. Metaphilosophy, 41, 313-330.

Scott-Phillips, T. C. (2008). Defining biological communication. Journal of Evolutionary Biology, 21, 387-395.

Searcy, W. \& Nowicki, S. (2005). The Evolution of Animal Communication. Princeton, NJ: Princeton University Press.

Seyfarth, R. M. \& Cheney, D. L. (2003). Signalers and receivers in animal communication. Annual Review of Psychology, 54, 145-173. 
Seyfarth, R. M., Cheney, D. L., Bergman, T. et al. (2010). The central importance of information in studies of animal communication. Animal Behaviour, 80, 3-8.

Seyfarth, R. M., Cheney, D. L. \& Marler, P. (1980). Vervet monkey alarm calls: semantic communication in a free-ranging primate. Animal Behaviour, 28, 1070-1094.

Shannon, C. E. (1948). The mathematical theory of communication, I and II. Bell System Technical Journal, 27, 379-423, 623-656.

Shea, N. (2007). Consumers need information: supplementing teleosemantics with an input condition. Philosophy and Phenomenological Research, 75, 404-435.

Shettleworth, S. J. (2001). Animal cognition and animal behaviour. Animal Behaviour, 61, 277-286.

Shettleworth, S. J. (2010). Cognition, Evolution, and Behaviour, 2nd edn. Oxford: Oxford University Press.

Skyrms, B. (2010). Signals: Evolution, Learning, and Information. Oxford: Oxford University Press.

Slocombe, K. E. \& Zuberbühler, K. (2005). Functionally referential communication in a chimpanzee. Current Biology, 15(19), 1779-1784.

Smith, W. J. (1965). Message, meaning, and context in ethology. American Naturalist, 99, 405-409.

Smith, W.J. (1986). An 'informational' perspective on manipulation. In R.W. Mitchell \& N. S. Thompson, eds., Deception: Perspectives on Human and Nonhuman Deceit. Albany, NY: State University of New York Press, pp. 71-86.

Smith, W. J. (1997). The behavior of communicating, after twenty years. In D. H. Owings, M. D. Beecher \& N. S. Thompson, eds., Communication. Perspectives in Ethology, Vol. 12. New York: Plenum Press, pp. 7-53.

Sperber, D. \& Origgi, G. (2010). A pragmatic perspective on the evolution of language. In R. K. Larson, V. Déprez \& H. Yamakido, eds., The Evolution of Human Language: Biolinguistic Perspectives. Cambridge: Cambridge University Press, pp. 124-132.

Stegmann, U.E. (2005). John Maynard Smith's notion of animal signals. Biology and Philosophy, 20, 1011-1025.

Stegmann, U.E. (2009). A consumer-based teleosemantics for animal signals. Philosophy of Science, 76, 864-875.

Stephens, D. W. (2007). Models of information use. In D. W. Stephens, J. S. Brown \& R. C. Ydenberg, eds., Foraging: Behaviour and Ecology. Chicago, IL: University of Chicago Press, pp. 48-75.

Swaisgood, R. R., Rowe, M. P. \& Owings, D. H. (1999). Assessment of rattlesnake dangerousness by California ground squirrels: exploitation of cues from rattling sounds. Animal Behaviour, 57, 1301-1310.

Templeton, J.J. \& Giraldeau, L. A. (1996). Vicarious sampling: The use of personal and public information by starlings foraging in a simple patchy environment. Behavioral Ecology and Sociobiology, 38, 105-114.

Valone, T. J. (1989). Group foraging, public information, and patch estimation. Oikos, 56, 357-363.

Van Heijningen, C. A. A., De Visser, J., Zuidema, W. \& Ten Cate, C. (2009). Simple rules can explain discrimination of putative recursive syntactic structures by a 
songbird species. Proceedings of the National Academy of Sciences USA, 106,

20538-20543.

von Frisch, K. (1967). The Dance Language and Orientation of Bees. Cambridge, MA: Harvard University Press.

Wagner, R. H. \& Danchin, E. (2010). A taxonomy of biological information. Oikos, 119(2), 203-209.

Wheeler, B. C., Searcy, W. A., Christiansen, M. H. et al. (2011). Communication. In R. Menzel \& J. Fischer, eds., Animal Thinking: Contemporary Issues in Comparative Cognition. Cambridge, MA: MIT Press, pp. 187-205.

Wiley, R. H. (1983). The evolution of communication: Information and manipulation. In T. R. Halliday \& P.J. B. Slater, eds., Communication. Animal Behaviour, Vol. 2. Oxford: Blackwell, pp. 156-189.

Wilson, E. O. (1975). Sociobiology: The New Synthesis. Cambridge, MA: Harvard University Press.

Wingfield, J. C. \& Wada, M. (1989). Changes in plasma levels of testosterone during male-male interactions in the song sparrow, Melospiza melodia: time course and specificity of response. Journal of Comparative Physiology A, 166, 189-194.

Zahavi, A. (1975). Mate selection - a selection for a handicap. Journal of Theoretical Biology, 53, 205-259.

Zuberbühler, K., Cheney, D. L. \& Seyfarth, R. M. (1999). Conceptual semantics in a nonhuman primate. Journal of Comparative Psychology, 113, 33-42.

Zuberbühler, K., Ouattara, K., Bitty, A., Lemasson, A. \& Noë, R. (2009). The primate roots of human language: Primate vocal behaviour and cognition in the wild. In F. d'Errico \& J. Hombert, eds., Becoming Eloquent: Advances in the Emergence of Language, Human Cognition, and Modern Cultures. Amsterdam: John Benjamins Publishing Company, pp. 235-266. 